\title{
Economic Evaluation on the MOX Fuel in the Closed Fuel Cycle
}

\author{
Youqi Zheng, Hongchun Wu, Liangzhi Cao, and Shizhuang Jia \\ School of Nuclear Science and Technology, Xi'an Jiaotong University, Xi'an, Shaanxi 710049, China \\ Correspondence should be addressed to Youqi Zheng,yqzheng@mail.xjtu.edu.cn
}

Received 13 September 2012; Accepted 11 December 2012

Academic Editor: Hangbok Choi

Copyright (C) 2012 Youqi Zheng et al. This is an open access article distributed under the Creative Commons Attribution License, which permits unrestricted use, distribution, and reproduction in any medium, provided the original work is properly cited.

\begin{abstract}
The mixed oxide (MOX) fuel is one of the most important fuels for the advanced reactors in the future. It is flexible to be applied either in the thermal reactor like pressurized water reactor (PWR) or in the fast reactor (FR). This paper compares the two approaches from the view of fuel cost. Two features are involved. (1) The cost of electricity (COE) is investigated based on the simulation of realistic operation of a practical PWR power plant and a typical fast breeder reactor design. (2) A new economic analysis model is established, considering the discount rate and the revenue of the reprocessed plutonium besides the traditional costs in the processes of fuel cycle. The sensitivity of COE to the changing parameters is also analyzed. The results show that, in the closed fuel cycle, the fuel cost of applying MOX fuels in the FBR is about 25\% lower than that in the PWR at the current operating and fuel cycle level.
\end{abstract}

\section{Introduction}

The closed fuel cycle becomes more and more attractive in the fast development of nuclear industry. Many countries have executed or decided to execute such strategy. Especially in China, the nuclear energy expanded rapidly in the past several years. In the future, it is pointed that the nuclear power installation will be over $75 \mathrm{GWe}$ by 2020 . Huge amount of natural uranium is required. Large pressure is withstood for the low efficiency of current resources utilization. The closed fuel cycle strategy becomes the necessary choice.

The fabrication, application, and reprocessing of mixed oxide (MOX) fuel is one of the key technologies in the closed fuel cycle. By using the reprocessed plutonium, the utilization efficiency of uranium, which is defined as the mass of uranium consumed duo to per kilowatt hour electricity production, is significantly increased. The previous studies have shown that the utilizing of MOX fuel in the thermal reactors can increase the utilization efficiency by $20 \%-$ $30 \%$ [1]. If it is applied in the fast reactors (FRs), the efficiency can be increased by 20 times [2]. From 1996, the European union (EU) countries have used over 104 tons of plutonium in the thermal reactors and saved about $10 \%$ uranium [3]. Up to now, several fast reactors have been loaded with the MOX fuel and proved to be feasible [4].

In China, the closed fuel cycle strategy and the reusing of the recycled plutonium have been determined by the government. However, the way to reuse the plutonium is still need to be considered further, especially for the investor of nuclear power plant. The cost must be considered seriously. It sometimes dominates the decision. For the nuclear power plant, the MOX fuel can be used in both thermal and fast reactors. Therefore, it is useful to analyze the composition of cost while using the MOX fuel in different reactors and make the comparisons to suggest a better decision from the view of economics besides the technologies, and so forth.

The economic analysis on the fuel cycle has been paid attention to since years ago. In 1991, the Westinghouse applied the minimum revenue requirement method to analysis the economics of open and closed fuel cycles [5]. Owen and Omberg compared the economics of pressurized water reactor (PWR) and FR. They pointed out that the construction cost and fuel cost are the two main parts [6]. In 2003, Bunn and Fetter studied the economics of open and closed fuel cycles considering the MOX fuel, in which the reliability of economic parameters is specially evaluated [7].

In this study, the fuel costs of using the MOX fuels in PWR and FBR are investigated, considering the current 


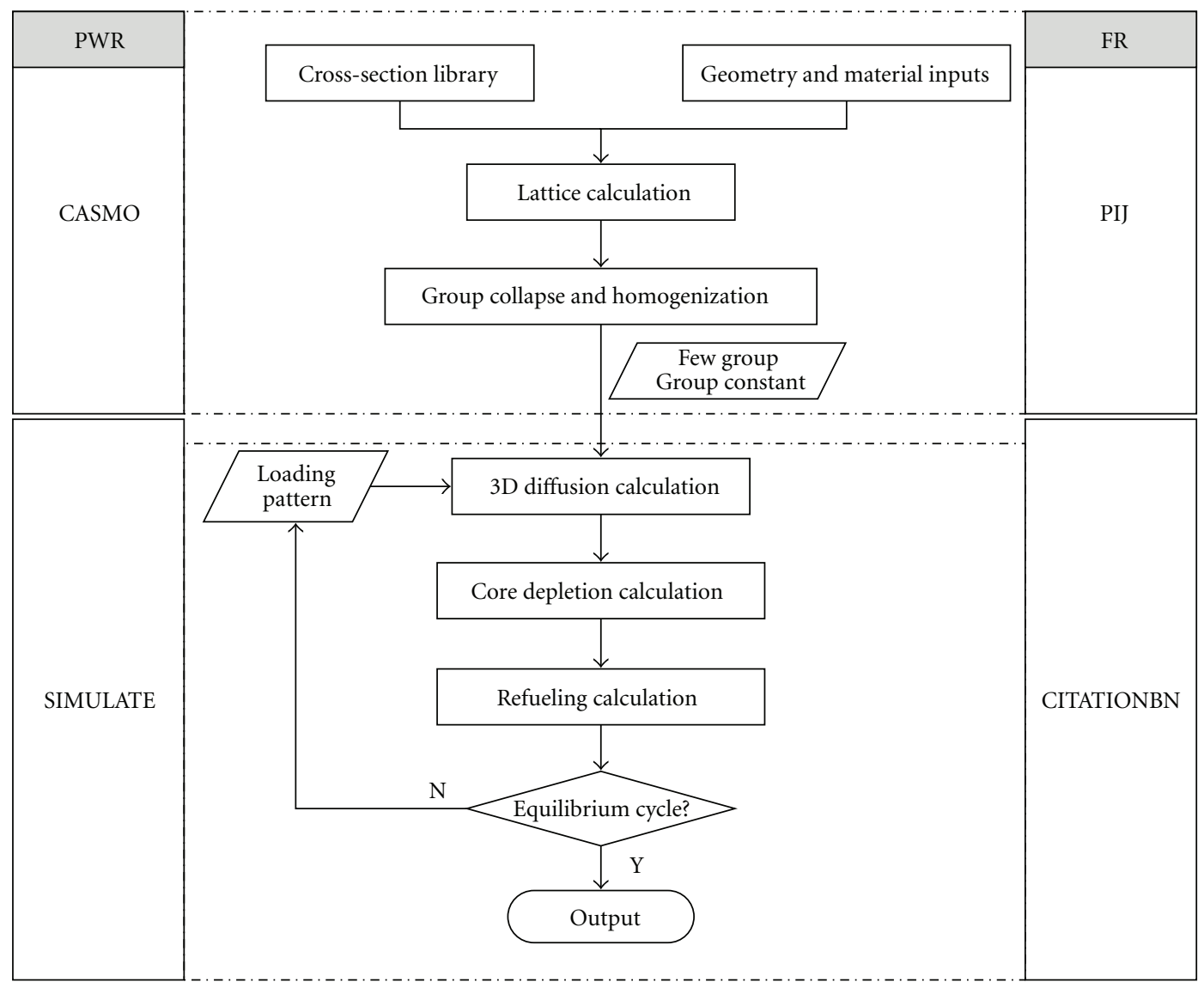

FIGURE 1: The computational flowchart of reactor core simulation.

design of reactors besides the economic parameters only. The operation of power plant is simulated by the reactor core analysis codes. The comparisons in the current or near future situation are analyzed. Also the sensitivity of the costs is predicted. The results show that the fuel cost of electricity (FCOE) in PWR with MOX fuel loaded is 25\% higher than that of in FBR. But the situation will be changed with the burnup and discount rate.

\section{Evaluation Methods}

2.1. Reactor Core Simulation Method. To simulate the operation of PWR with the MOX fuel loaded, the code package CASMO/SIMULATE $[8,9]$ is applied according to the computational flowchart as in Figure 1. For the fast reactor simulation, the code package PIJ/CITATIONBN is used. This is a home-developed code for fast reactor analysis, which is also based on the computational flowchart as in Figure 1.

2.2. Economic Analysis Method. To avoid the confusion from the differences of reactors, the fuel cost of electricity (FCOE) evaluated by the cost per kilowatt hour electricity production from the fuel cycle is applied in the analysis. The mass flow of heavy metal (including the uranium and plutonium) in the closed fuel cycle is illustrated in Figure 2. The differences between reusing the recycled plutonium in
PWR and FBR arise in two main aspects. (1) Even after loading the plutonium, the fuels in PWR still consist of the MOX fuel and the necessary $\mathrm{UO}_{2}$ fuel. Therefore, the cost is contributed from both the two kinds of fuels. (2) The plutonium bred in the FBR is valuable for further use. The feed material of FBR is contributed from two sources, that is, the recycled plutonium from PWR spent fuel and the plutonium bred in FBR.

Cash flow as in Figure 3 depicts the main costs of MOX fuel in the fuel cycle. The horizontal axis represents the timeline, and the sizes of bars represent nominal costs associated with the subscripted processes. As in the figures, the values above the horizontal axis denote the cost, while the below ones denote the revenue. Here, the time $t_{o m}$, at which the fuels are consumed for generating the electricity, is appointed as the reference time. $P$ - and $F$ - stand for the variables in the PWR and FBR, respectively. $C_{u}, C_{c}, C_{s}$, and $C_{l f}$ are the costs of original uranium, chemical conversion of $\mathrm{UF}_{6}$, separative work and enriching process, and $\mathrm{UO}_{2}$ fuel assembly fabrication, respectively. $t_{u}, t_{c}, t_{s}$, and $t_{l f}$ are the times at which these costs are paid relative to $t_{o m}$. $C_{r}, C_{d h}$, $C_{D U}$, and $C_{m f}$ are the costs of reprocessing the spent $\mathrm{UO}_{2}$ fuel assemblies, disposal of the high-level waste (HLW), depleted uranium (from the tails in enriching process) purchasing, and MOX fuel assembly fabrication at $t_{r}, t_{d h}, t_{D U}$, and $t_{m f}$, respectively. When the fuels are ready, they will be loaded 


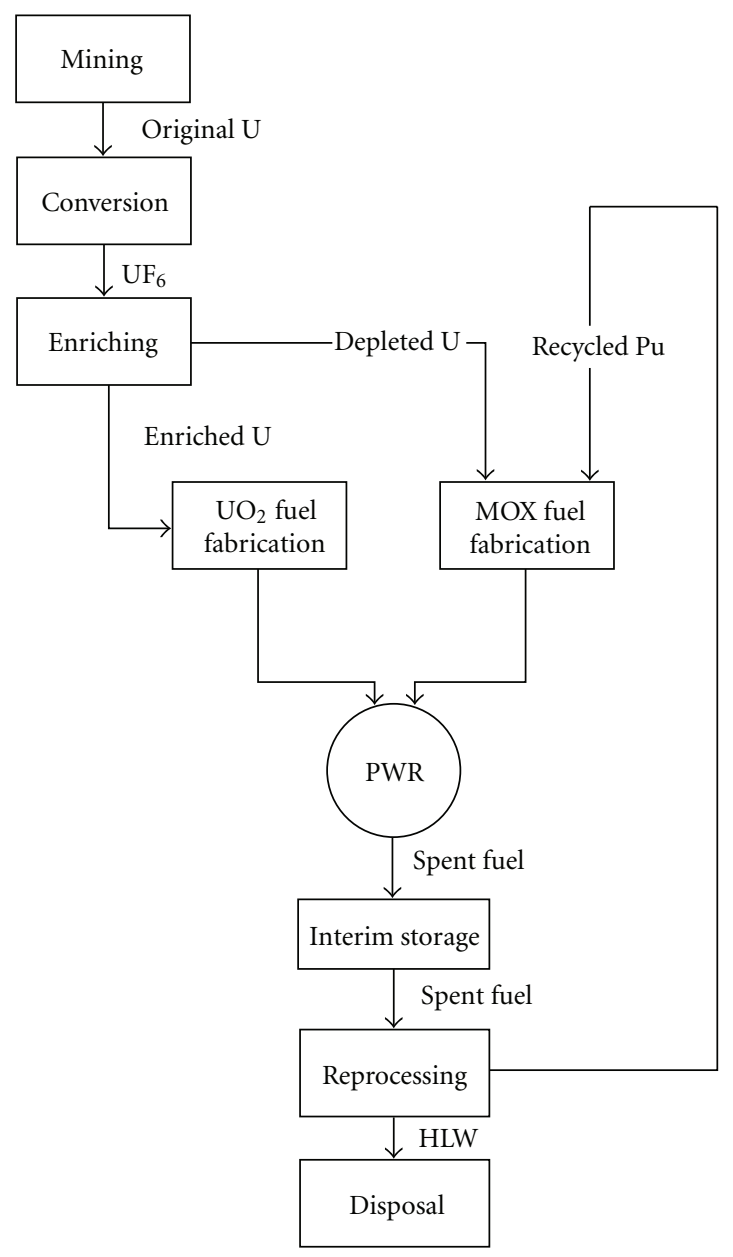

(a) PWR

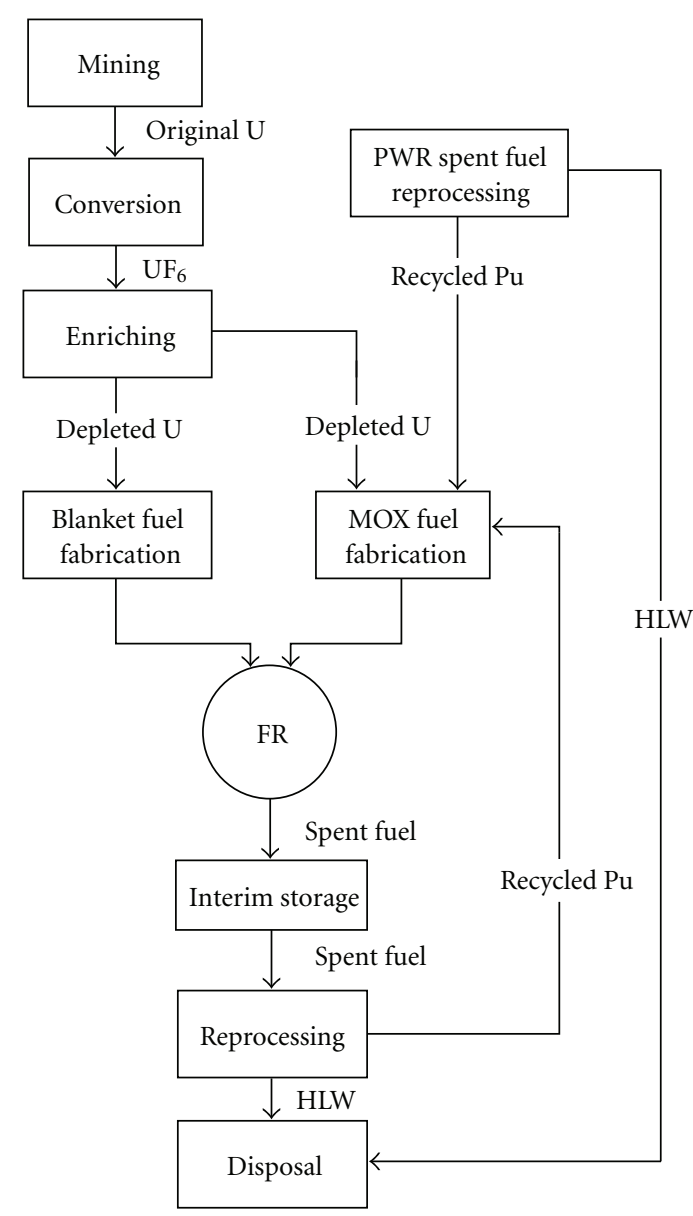

(b) FBR

Figure 2: The mass flow of heavy metal in the closed fuel cycle.

in reactor. $C_{m d}$ and $C_{l d}$ are taken as the total costs of interim storage and disposal of the MOX fuel and $\mathrm{UO}_{2}$ fuel after discharging, respectively. For the fast breeder reactor, it should be noted that the plutonium from breeding is taken as the revenue. $C_{b d}$ is the total cost of fuels in the blanket of FBR after discharging.

The cost of a power plant consists of the capital cost, fuel cost, annual cost, and so forth. This study focuses only on the fuel costs.

For the PWR, due to the limit of loading fraction, two kinds of fuels should be considered together, that is, the $\mathrm{UO}_{2}$ fuel and the MOX fuel. The cost is formulated as:

$$
C_{\mathrm{PWR}}=w \frac{C_{P-\mathrm{MOX}} F_{c, \mathrm{MOX}}}{24,000 \mathrm{BU} \mathrm{MOX}_{\mathrm{MO}} \varepsilon}+(1-w) \frac{C_{P-\mathrm{UO}_{2}} F_{c, \mathrm{UO}_{2}}}{24,000 B_{\mathrm{UO}_{2}} \varepsilon},
$$

where $w$ is the power fraction of MOX fuel in the reactor core and $\varepsilon$ is the thermal efficiency of the power plant $\left(\mathrm{kW}_{e} / \mathrm{kW}_{t}\right)$. $C_{P-\mathrm{MOX}}$ and $\mathrm{C}_{\mathrm{P}-\mathrm{UO}_{2}}$ are the costs of MOX fuel and $\mathrm{UO}_{2}$ fuel, respectively. The carrying charge factor, $F_{c}$ (usually smaller than 1.0), accounts for the fact that the electricity revenue to pay for the disposal over the time $\tau$ as in (2), BU, is the discharging burnup. Then,

$$
F_{c}=\frac{\tau i}{(1+i)^{\tau}-1}
$$

where $i$ denotes the discount rate.

The costs of $\mathrm{UO}_{2}$ fuel and MOX fuel are obtained according to the material flow and cash flow described above. They are represented as follows:

$$
\begin{gathered}
C_{P-\mathrm{UO}_{2}}=C_{u}^{\prime}+C_{c}^{\prime}+C_{s}^{\prime}+C_{l f}^{\prime}+C_{l d}^{\prime}, \\
C_{P-\mathrm{MOX}}=C_{r}^{\prime}+C_{d h}^{\prime}+C_{D U}^{\prime}+C_{m f}^{\prime}+C_{m d}^{\prime},
\end{gathered}
$$

where $P$ - denotes the variable related to the PWR. $C_{u}^{\prime}, C_{c}^{\prime}$, $C_{s}^{\prime}, C_{l f}^{\prime}$, and $C_{l d}^{\prime}$ represent the same variables as in Figure 3. The superscript denotes that the losses including the loss of material and capital in these processes are considered.

For the fast breeder reactor, there are also two types of fuel assemblies. The seed assemblies, made from the MOX fuel, produce most of the energy for generating the electricity. The blanket assemblies, which contain only 


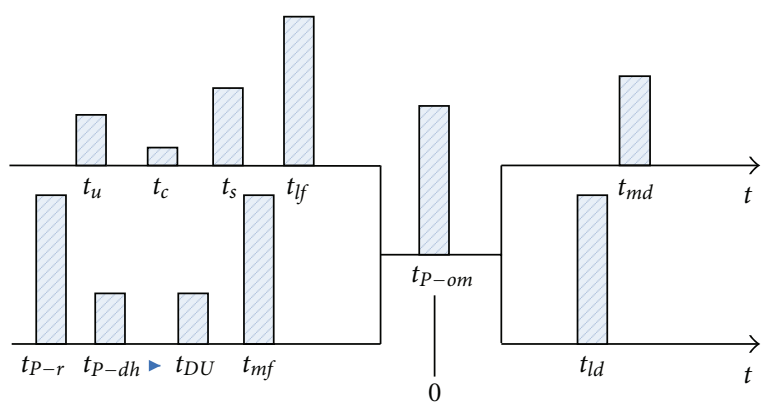

(a) PWR

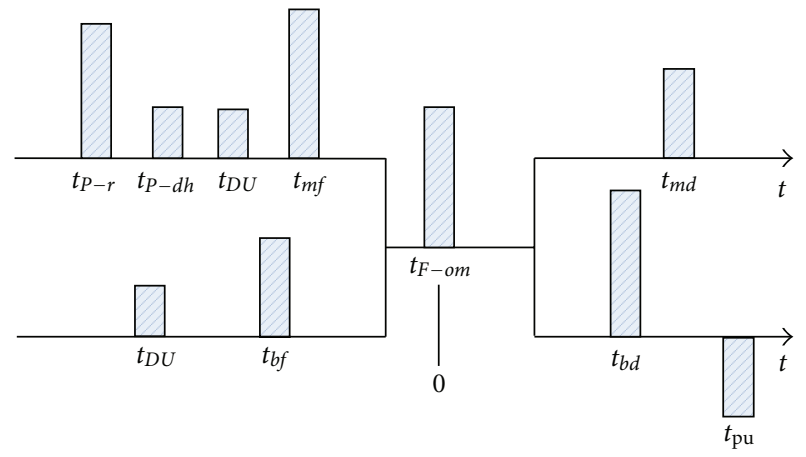

(b) FBR

FIgURE 3: The cash flow in the closed fuel cycle.

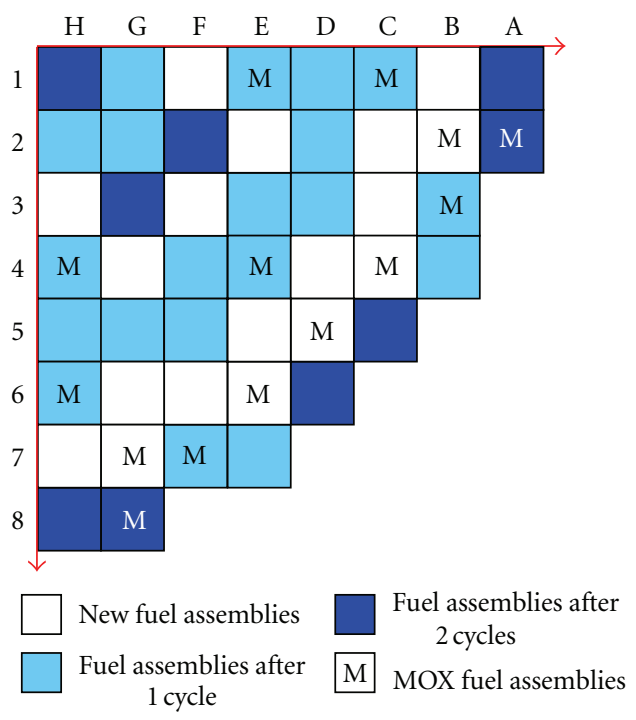

FIgURE 4: The loading pattern of fuel assemblies in the PWR.

depleted uranium, breed the plutonium with small fraction of electricity production. Therefore, the composition of fuel cost is

$$
C_{\mathrm{FR}}=\frac{\left(C_{c}+C_{\mathrm{ab}}\right) F_{c}+C_{\mathrm{rb}} F_{\mathrm{rb}}}{24,000 \mathrm{BU} \varepsilon}-\frac{M_{P_{u}} C_{P_{u}} F_{c}}{(1+i)^{t_{u}} 24,000 \mathrm{BU \varepsilon} \varepsilon},
$$

where $C_{c}, C_{\mathrm{ab}}$, and $C_{\mathrm{rb}}$ are the cost in seed assemblies, axial blankets, and radial blankets, respectively. They are

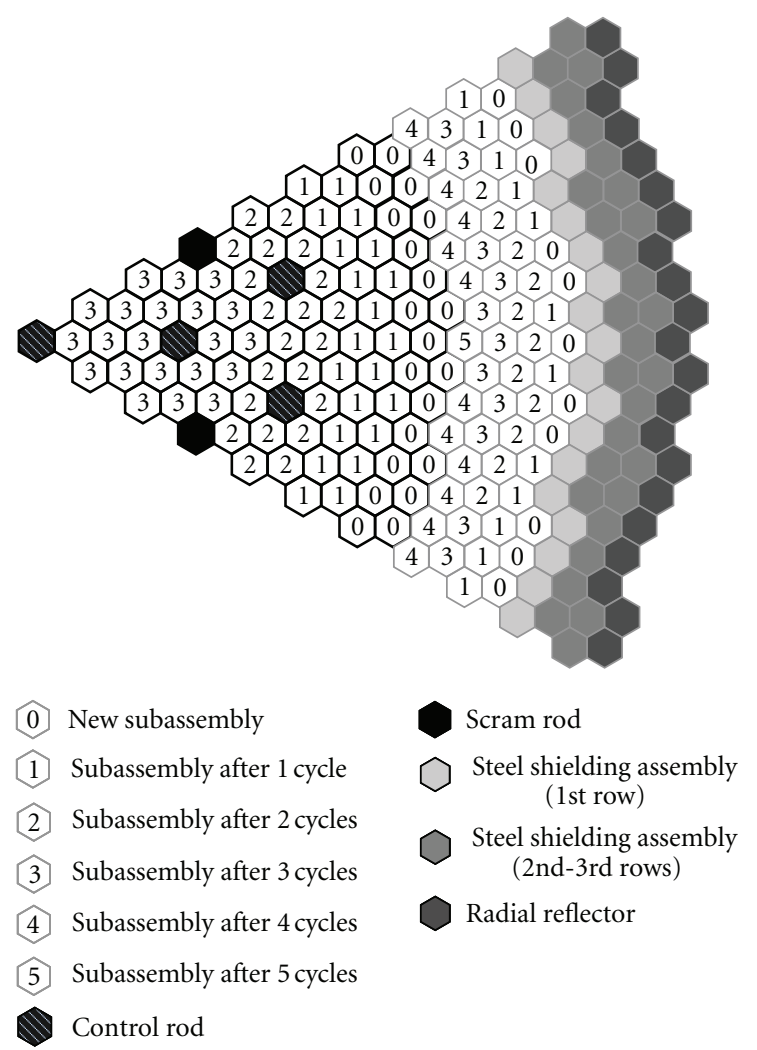

Figure 5: The loading pattern of fuel assemblies in the fast reactor.

determined depending on the material and cash flow as follows:

$$
\begin{gathered}
C_{C-\operatorname{mox}}=C_{r}^{\prime}+C_{d h}^{\prime}+C_{D U}^{\prime}+C_{m f}^{\prime}+C_{m d}^{\prime}, \\
C_{a-b}=C_{a-D U}^{\prime}+C_{a-b f}^{\prime}+C_{a-m d}^{\prime}, \\
C_{r-b}=C_{r-D U}^{\prime}+C_{r-b f}^{\prime}+C_{r-m d}^{\prime},
\end{gathered}
$$

where $F$ - denotes the variable related to the FBR.

For the fast breeder reactor, the discharged plutonium from breeding is very important and can be further used in other fast reactors. It is considered as the potential revenue. The benefit is represented as in (4). $C_{P u}$ is the revenue of recycled plutonium from breeding. $M$ represents the mass.

Additionally, a special issue should be noticed, and the plutonium should be stored for some time before it is fabricated into the new fuel assemblies. However, it is expensive to keep the reprocessed plutonium securely. The additional cost should be involved.

\section{Simulation of the PWR and FBR with MOX Fuel Loaded}

3.1. Performance of PWR with MOX Fuel Loaded. The M310type PWR is chosen in the simulation for its common installation. However, limited by the safety factors, the fraction of MOX fuel in the reactor core should not exceed $30 \%$ due to the change by the plutonium [1]. 


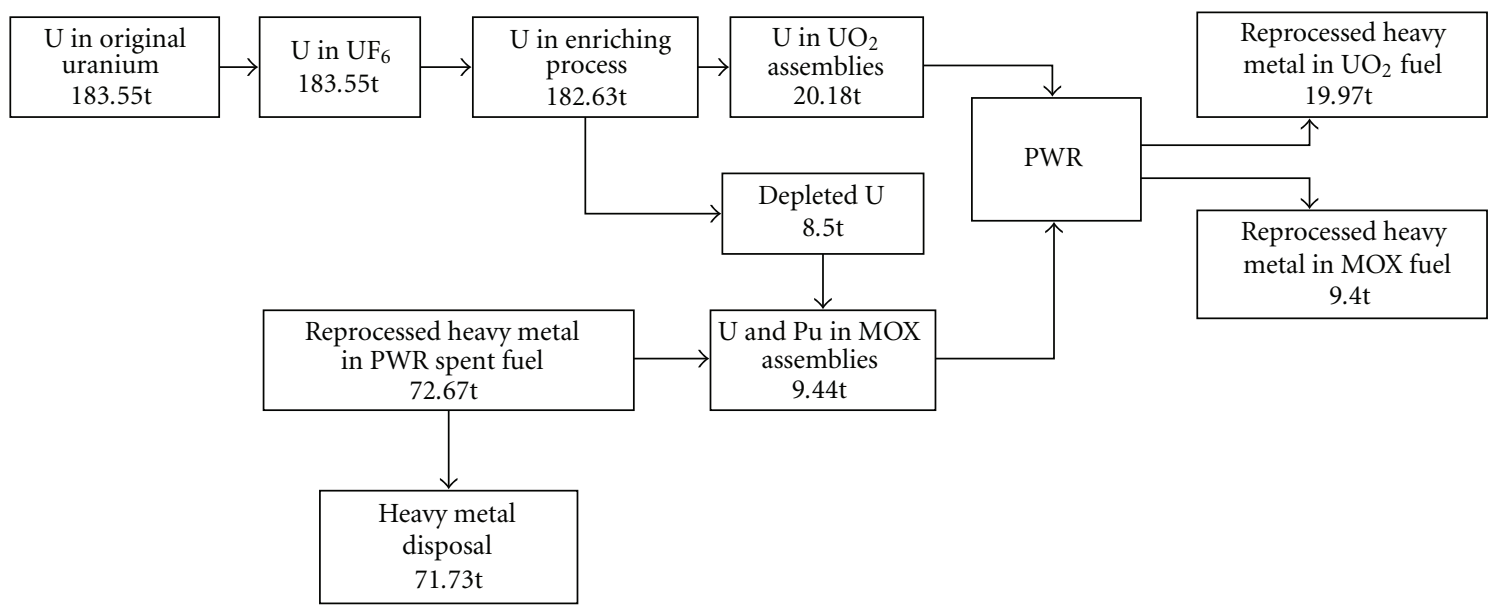

(a) PWR

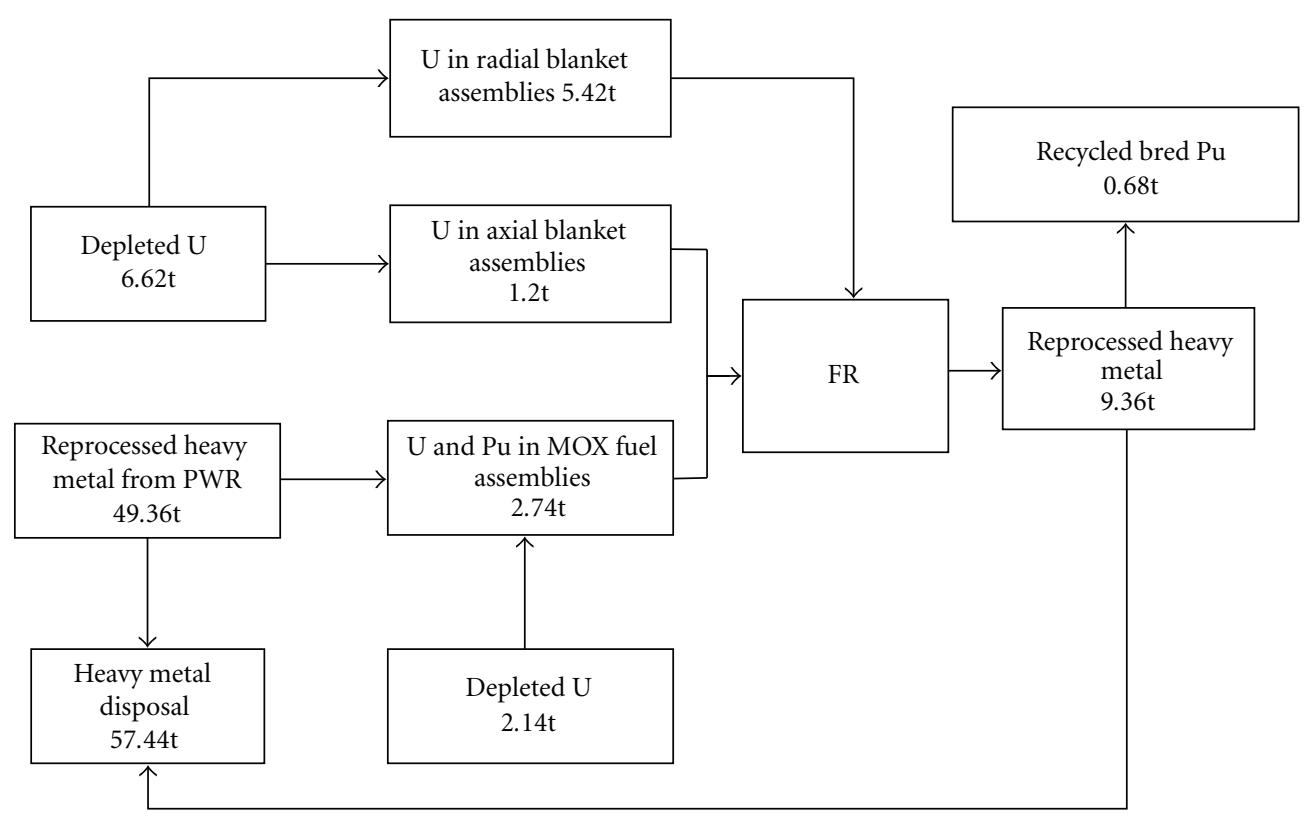

(b) Fast reactor

Figure 6: The mass balance of heavy metal in the closed fuel cycle.

In the original reactor core, only the $\mathrm{UO}_{2}$ fuel assemblies are loaded. The MOX fuel assemblies are imported batch by batch. The plutonium in MOX fuel is reprocessed from the current PWR spent fuels. The composition is given as in Table 1.

The refueling scheme is illustrated as in Figure 4. The in-out refueling scheme with low-leakage consideration is adopted. After refueling five times, the new equilibrium cycle is obtained. A total of, $48 \mathrm{MOX}$ fuel assemblies are loaded in the reactor core. The fraction is $30 \%$, similar with the mostly common case in the EU PWR power plants [3]. The reactor performances in the equilibrium cycle are given in Table 2. It indicates that, in this reactor core design, loading MOX fuel does not bring significant changes in the core performance compared with the traditional $\mathrm{UO}_{2}$-fueled PWR.
3.2. Performance of FBR with MOX Fuel Loaded. The BN600type fast reactor is chosen as the basis for its success operation experience [10]. The composition of plutonium in the MOX fuel is the same with the one in PWR, but the weight percent is higher, up to $22.05 \%$.

There are two options in developing a fast reactor, one is called the breeder reactor, and the other is called the burner reactor. In this study, the breeder reactor is investigated only since the economics of the burner is not so meaningful. From this point, the core design is improved from the current BN600's. The radial blanket is added to enhance the breeding and make the conversion ratio bigger than 1.0. The loading pattern is illustrated as in Figure 5, mainly based on the original design, but four rings of blanket assemblies are arranged outside the driver. A total of 474 seed assemblies and 336 blanket assemblies are loaded. 


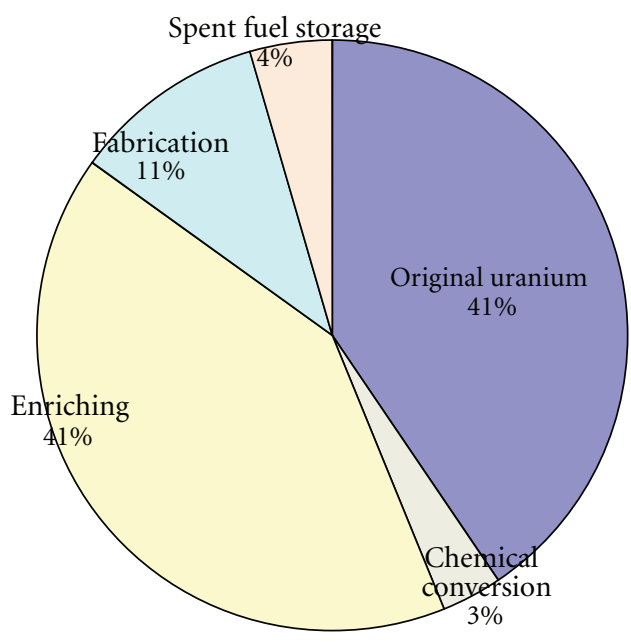

(a) $\mathrm{UO}_{2}$ fuel

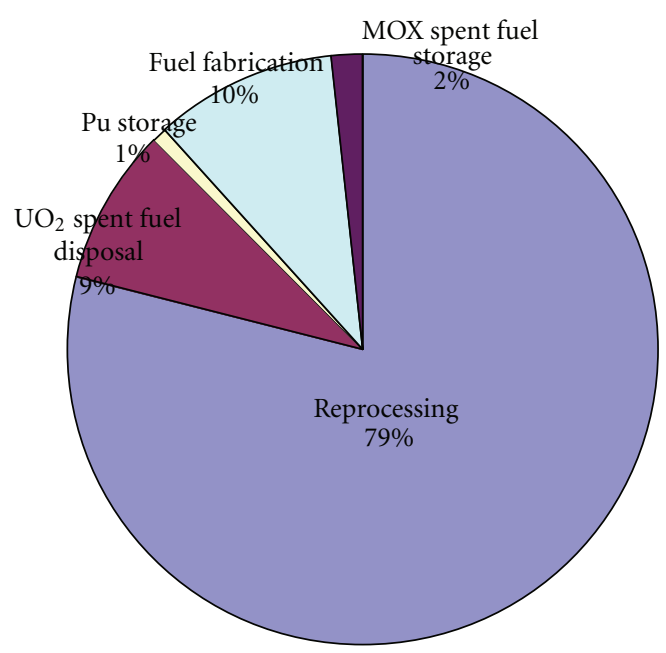

(b) MOX fuel

FIgURE 7: The cost compositions of $\mathrm{UO}_{2}$ and MOX fuels.

TABLE 1: The composition of reprocessed plutonium.

\begin{tabular}{lccccc}
\hline Isotopes & ${ }^{238} \mathrm{Pu}$ & ${ }^{239} \mathrm{Pu}$ & ${ }^{240} \mathrm{Pu}$ & ${ }^{241} \mathrm{Pu}$ & ${ }^{242} \mathrm{Pu}$ \\
\hline Mass percent/\% & 2.85 & 52.28 & 23.33 & 15.20 & 6.34 \\
\hline
\end{tabular}

TABLE 2: The reactor core performance of PWR with MOX fuel loaded.

\begin{tabular}{lc}
\hline Items & Value \\
\hline Length of cycle $\left(\mathrm{EFPD}^{1}\right)$ & 480 \\
Maximum burnup of $\mathrm{UO}_{2}$ assembly $\left(\mathrm{GWd} / \mathrm{tHM}^{2}\right)$ & 53.02 \\
Maximum burnup of $\mathrm{MOX}^{2}$ assembly $(\mathrm{GWd} / \mathrm{tHM})$ & 49.56 \\
Average burnup of $\mathrm{UO}_{2}$ assembly $(\mathrm{GWd} / \mathrm{tHM})$ & 46.69 \\
Average burnup of $\mathrm{MOX}$ assembly $(\mathrm{GWd} / \mathrm{tHM})$ & 47.11 \\
Critical concentration of boric solution, BOL $\left(\mathrm{ppm}^{3}\right)$ & 1773 \\
Enthalpy rising factor, BOL & $\mathrm{EOL}^{5}$ \\
Axial power peak factor, BOL/EOL & $1.51 / 1.34$ \\
Radial power peak factor, BOL/EOL & $1.47 / 1.33$ \\
\hline
\end{tabular}

${ }^{1}$ Effective full power day. ${ }^{2}$ Tons of heavy metal. ${ }^{3}$ Parts per million. ${ }^{4}$ Beginning of life. ${ }^{5}$ End of life.

The out-in refueling scheme is designed. Figure 5 also shows the refueling scheme. In each refueling process, 120 new seed assemblies and 66 blanket assemblies are loaded. The seed assemblies are totally renewed after 4 batches of refueling, and the blanket assemblies are renewed after 5 batches of refueling.

The reactor performances are simulated by using PIJ/CITATION. After 10 batches of refueling, the equilibrium cycle can be obtained. The parameters are obtained as in Table 3. The averaged burnup reaches $105.19 \mathrm{GWd} / \mathrm{tHM}$. The consumption of plutonium in each cycle is 0.6 tons with the conversion ratio bigger than 1.0. It is also consistent with the common core performance of fast breeder reactor.
TABle 3: The reactor core performance of FBR with MOX fuel loaded.

\begin{tabular}{lc}
\hline Items & Value \\
\hline Length of cycle (EFPD) & 225 \\
Reactivity loss $(\Delta \mathrm{k} / \mathrm{k} \%)$ & 4.25 \\
Average burnup $(\mathrm{GWd} / \mathrm{tHM})$ & 105.19 \\
Max. burnup (GWd/tHM) & 113.13 \\
Mass of plutonium loading (ton) & 0.6 \\
Mass of discharged plutonium from blankets each & 0.192 \\
cycle (ton) & \\
Power fraction in the seed assemblies, BOC/EOC & $96.62 / 93.78$ \\
(\%) & $1.239 / 1.199$ \\
Axial power peak factor, BOC/EOC & $1.197 / 1.197$ \\
Axial power peak factor, BOC/EOC & 38.9 \\
Max. linear power density (kw/m) & $1.09 / 1.137$ \\
Conversion ratio, BOC/EOC
\end{tabular}

Based on the simulation, the mass balance can be obtained from the following economic analysis. Besides, the discharging parameters are also necessary to analyze the FCOE. Since all the core performances in PWR and FBR do not deviate from the traditional conditions of current $\mathrm{UO}_{2}$-fueled reactors, no excess changes should be considered further in operating the reactors due to loading the MOX fuel.

\section{Economic Analysis}

4.1. Analysis in Current Level. The price in the processes of fuel cycle is the most important economic parameter. The price used in this study is cited from the website http://www.uxc.com and the literature [6]. Table 4 summarizes the data, and its reference change interval for sensitivity analysis. 
TABLE 4: The price of processing techniques and its change interval in the fuel cycle.

\begin{tabular}{|c|c|c|c|c|}
\hline \multirow{2}{*}{ Items } & \multicolumn{2}{|c|}{ Unit (\$/kgHM) } & \multirow{2}{*}{ Time lag (month) } & \multirow{2}{*}{ Material loss (\%) } \\
\hline & Current level & Reference change interval & & \\
\hline Price of original uranium & 109.2 & $80 \sim 300$ & -18 & \\
\hline Price of chemical conversion & 9.23 & $6.42 \sim 12.84$ & -12 & 0.5 \\
\hline Price of $\mathrm{UO}_{2}$ fuel fabrication & 275 & $200 \sim 350$ & -6 & 1.0 \\
\hline Price of $\mathrm{UO}_{2}$ spent fuel reprocessing & 2107 & $940 \sim 3712$ & -24 & 0.5 \\
\hline Price of reprocessed uranium (RU) & 20 & $0 \sim 100$ & -24 & \\
\hline Price of plutonium storage/\$/kgy & 1200 & $1000 \sim 1300$ & $-24 \sim-6$ & \\
\hline Price of tails & 12 & $7 \sim 36$ & -12 & \\
\hline Price of depleted uranium & 6 & $0 \sim 100$ & -12 & \\
\hline Price of MOX fuel fabrication for PWR & 2215 & $838 \sim 2754$ & -6 & 0.5 \\
\hline Price of MOX fuel fabrication for FBR & 2400 & $1435 \sim 3350$ & -6 & 0.5 \\
\hline Price of blanket fuel fabrication for FBR & 275 & $200 \sim 350$ & -6 & 0.5 \\
\hline Price of MOX spent fuel storage & 470 & $360 \sim 580$ & 54 & \\
\hline Price of recycled plutonium from FBR & 2347 & $1060 \sim 4072$ & 60 & \\
\hline Discount rate & $5 \%$ & $2 \% \sim 8 \%$ & & \\
\hline
\end{tabular}

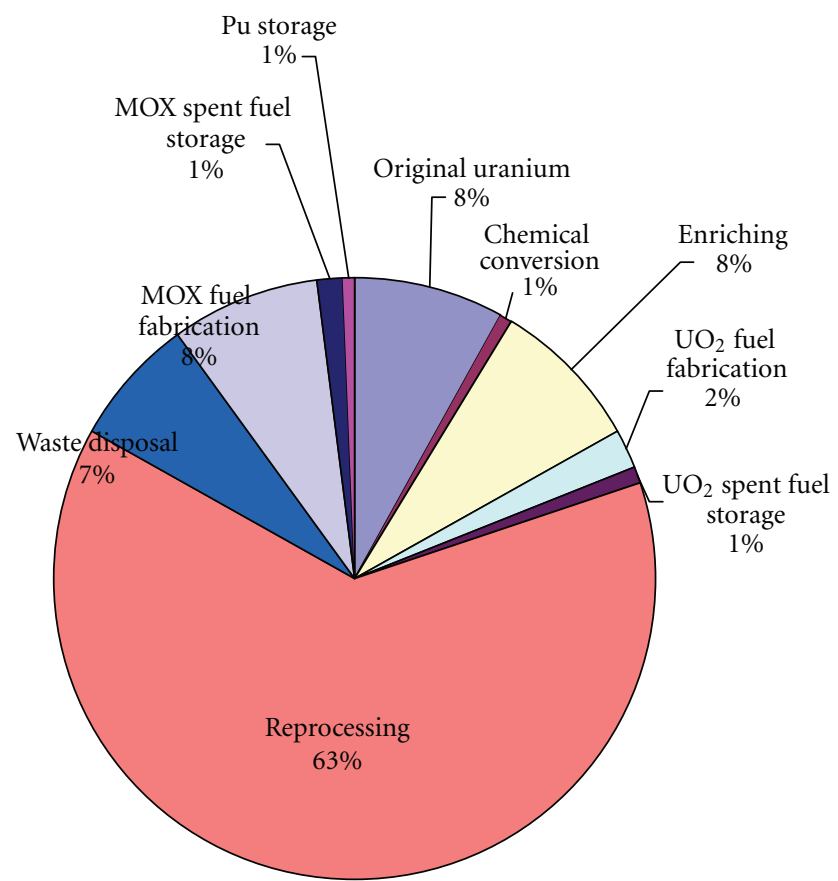

FIgUre 8: The FCOE composition of using MOX fuel in the PWR.

According to the simulation on the M310-type PWR and BN600-like fast breeder reactor, the mass balance based on the mass flow as in Figure 2 is determined. The results are shown in Figure 6, in which the preprocesses for getting the depleted uranium is omitted in the FBR cycle for simplification.

For the PWR loaded with MOX fuel (up to 30\%), the amount of required plutonium equals to the reprocessed mass from three PWR in the same scale. In this case, the uranium resources can be saved over $10 \%$. If the currently reserved PWR spent fuels are used, the fraction will be increased to over $30 \%$.

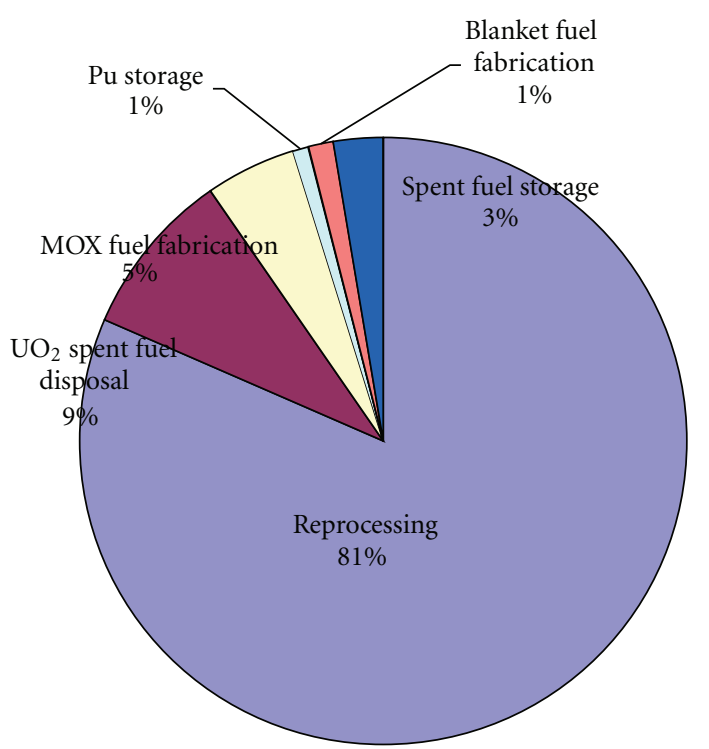

FIgURE 9: The FCOE composition of using MOX fuel in the FBR.

The final price of MOX fuel reaches 22720 dollar per kilogram $(\$ / \mathrm{kgHM})$, which is about 8.5 times higher than the one of current $\mathrm{UO}_{2}$ fuel. Figure 7 illustrates the composition of the price. The reprocessing cost dominates the fuel cost, which is different from the $\mathrm{UO}_{2}$ fuel, whose main part consists of the cost of original uranium and enriching process.

The final FCOE of PWR is $2.43 \$ / k w h$. Figure 8 illustrates the composition. For the PWR, the main cost in the fuel cycle is the one arises in reprocessing. The FCOE of FBR is $1.83 \$ / \mathrm{kwh}$; it is even lower than the one in PWR. It is contributed from the revenue of plutonium bred in the blankets. Here, the revenue accounts for $55 \%$ of the final FCOE $(4.10 \$ / k w h)$, that is, $2.27 \$ / k w h$. Figure 9 illustrates the composition excluding the revenue. 


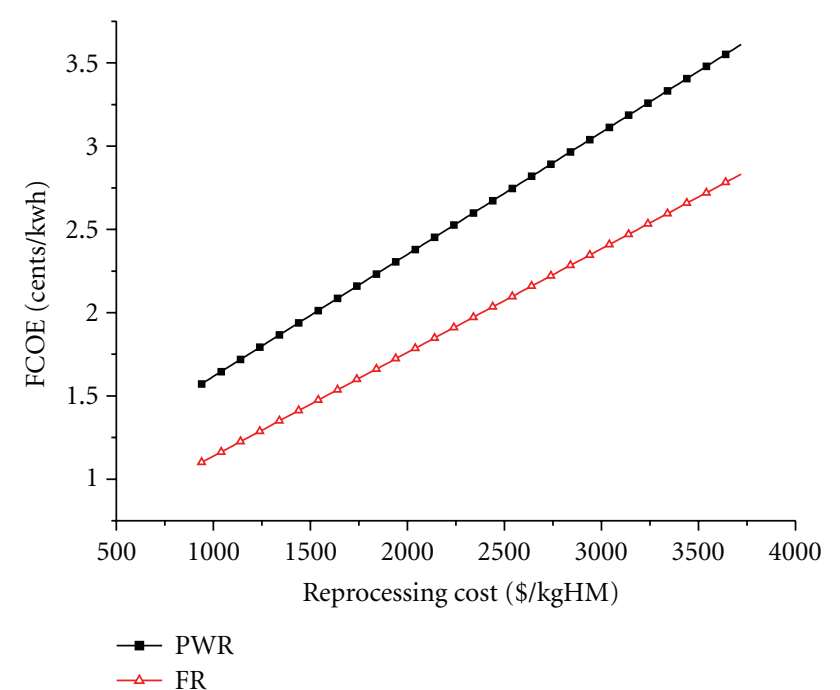

FIgURE 10: The changes of FCOE with reprocessing cost.

In this study, the typical design of a breeder reactor is investigated. Without considering the revenue in some fast reactors like ABR [11] (advanced burner reactor designed by Argonne National Laboratory), the cost will significantly increase. It will be about twice as much as the one of PWR. However, considering the revenue, the FCOE is 25\% lower than the one of PWR with 30\% MOX fuel loaded.

4.2. Sensitivity Analysis. For the economic analysis, the uncertainty of parameters is quite important due to many complicated factors. The sensitivity analysis is necessary. In this study, the sensitivity is investigated by defining the coefficient of elasticity as:

$$
\varepsilon_{y, x_{0}}=\left.\frac{d y / y}{d x / x}\right|_{x=x_{0}}=\frac{x_{0}}{y\left(x_{0}\right)} y^{\prime}\left(x_{0}\right)
$$

Among the costs in the fuel cycle, the reprocessing cost accounts for the largest proportion, either in PWR or in FBR. Figure 10 shows the change of FCOE against the reprocessing cost. Linear increase arises with the increase of reprocessing cost. Based on (6), the coefficients of elasticity are 0.64 and 0.72 , respectively. It means that if $1 \%$ increase of the reprocessing cost happens, the FCOE of PWR will increase by $0.64 \%$ and the one of FBR will increase by $0.72 \%$, that is, the FCOE of PWR increases by 0.016 cents, and the one of FBR increases by 0.013 cents.

The practical design and operation of reactors also impact heavily on the costs. For FCOE, the coefficients of elasticity are -0.99 for both PWR and FBR. It means that $1 \%$ increase of burnup contributes about $0.99 \%$ decrease of the FCOE, which is more attractive in PWR for its higher FCOE at current value. Figure 11 illustrates the change of FCOE against burnup in PWR and FBR, respectively. The reference costs are given, which are the current value of FCOE of FBR

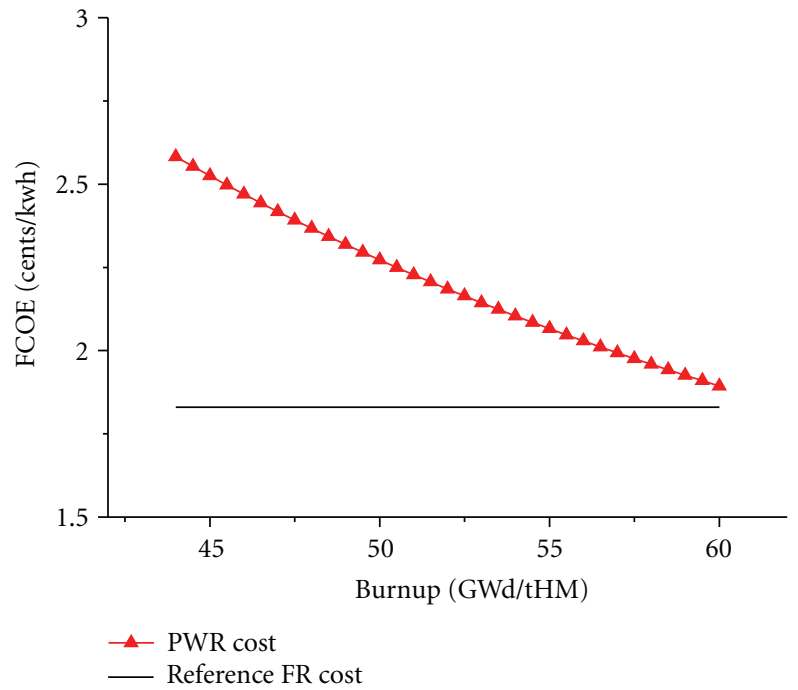

(a) PWR

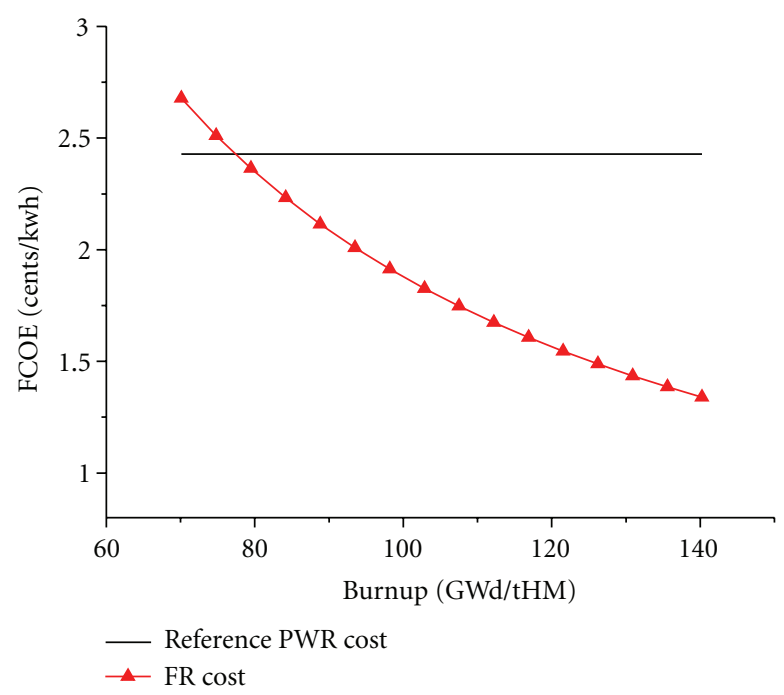

(b) FBR

FIgUre 11: The changes of FCOE with burnup.

and PWR, respectively. It indicates that if the burnup of PWR can be increased up to $62 \mathrm{GWd} / \mathrm{tHM}$, the FCOE will be smaller than the one of current FBR even if the revenue of plutonium is considered. In another aspect, if the burnup of FBR cannot reach the value as designed in this study, the FCOE of FBR will increase. If the value is lower than $80 \mathrm{GWd} / \mathrm{tHM}$, the FCOE of PWR will be lower, also even if the revenue of plutonium is considered.

The discount rate is very important for the FBR, because the FCOE of FBR is impacted significantly by the revenue of reprocessed plutonium. Unfortunately, the plutonium cannot be immediately applied. The plutonium should be carefully stored as it costs a lot. Due to the effect of time lag, the cost will be increased. The coefficient of elasticity for the FBR is 0.73 , which is 10 times larger than the one of PWR. 
If the discount rate is greater than $8 \%$, the FCOE of FBR is larger than the one of PWR.

Additionally, the original uranium cost is thought to be sensitive for PWR, since most of the fuels are still the $\mathrm{UO}_{2}$ fuels. However, the analysis indicates that the coefficient of elasticity is only 0.081 at current price of original uranium. This factor becomes insignificant.

\section{Conclusion}

In this study, the economics of MOX fuel in the closed fuel cycle is analyzed. Considering the two options of applying the MOX fuel, the cost of PWR and FBR are investigated, respectively. The FCOE is used as the evaluation parameter. To find the valuable conclusion, the operations of a typical PWR and FBR are simulated using the reactor core analysis codes. The economic analysis model is established, considering all the components in the closed fuel cycle, especially the revenue of reprocessed plutonium and capital loss in the time lag.

The FCOE of PWR and of FBR are obtained based on the reactor parameters in the equilibrium cycles. For the PWR, the FCOE is $2.43 \mathrm{c} / \mathrm{kwh}$, and for the FBR, the FCOE is $4.10 \mathrm{\$} / \mathrm{kwh}$. If the value of the reprocessed plutonium from breeding is considered, the cost will be reduced to $1.83 \$ / \mathrm{kwh}$, which is even lower than the one of PWR. The results are sensitive to the cost of reprocessing. The FCOE linearly increases with the increase of reprocessing cost in both PWR and FBR, where the PWR's FCOE keeps larger. Besides, the FCOE changes sensitively to the burnup and discount rate. With the increase of burnup in PWR or the decrease of burnup in FBR, the FCOE of PWR will become smaller than the one of FBR, even after considering the revenue of breeding. If the discount rate is large, the value of plutonium from breeding will be reduced. Also, the FCOE of PWR will be smaller.

Although it is only a part of the whole costs in constructing and operating a power plant, the FCOE is one of the most important influencing factors in the daily operation. This study gives the comparison of FCOE in different MOX fuel-loaded reactors. It will be useful to analyze the effect of utilizing the MOX fuel in the future closed fuel cycle.

\section{Acknowledgment}

This paper was carried out partly under the financial support of the National Natural Science Foundation of China (Approved no. 11105104).

\section{References}

[1] P. Bernard, "French experiences and perspectives on plutonium recycling in the existing power fleet," AREVA-COGEMA Recycling Business Unit, vol. 49, no. 8, pp. 583-588, 2007.

[2] Z. Gu and G. Ye, "Recent developments in studies of advanced nuclear fuel cycle system," Atomic Energy Science and Technology, vol. 36, no. 2, pp. 97-104, 2002.
[3] J. Provost, M. Schrader, and S. Nomura, "MOX fuel fabrication and utilization in LWRs worldwide," in MOX Fuel Cycle Technologies For Medium and Long Term Deployment, Vienna, Austria, 1999.

[4] J. Leclere, Y. Bibilashvili, F. Reshetnikov et al., "MOX fuel fabrication and utilization in fast reactor worldwide," in MOX Fuel Cycle Technologies For Medium and Long Term Deployment, Vienna, Austria, 1999.

[5] J. Zhu, A. Nechaev, and M. Tauched, Nuclear Fuel Cycle Training, Westinghouse Proprietary, Pennsylvania, Pa, USA, 1992.

[6] A. Waltar and A. Reynolds, Fast Breeder Reactor, Pergamon Press, Oxford, UK, 1981.

[7] M. Bunn and S. Fetter, The Economic of Reprocessing Vs. Direct Disposal of Spent Nuclear Fuel, Project on Managing the Atom, Cambridge, Mass, USA, 2003.

[8] "CASMO-4: A Fuel Assembly Burn-up Program User's Manual," SSP-09/443-U Rev 0, Studsvik, UK, 2009.

[9] "SIMULATE-3: Advanced Three-Dimensional Two-Group Reactor Analysis Code," SSP-09/447-U Rev 0, Studsvik, UK, 2009.

[10] P. Nporpammbi, "Updated codes and methods to reduce the calculational uncertainties of the LMFR reactivity effects," in The 5th Research Co-Ordination Meeting, Vienna, Austria, November, 2004.

[11] E. Hoffman, W. Yang, and R. Hill, "Preliminary Core Design Studies for the Advanced Burner Reactor over a Wide Range of Conversion Ratios," ANL-AFCI-177, Argonne National Laboratory, 2006. 

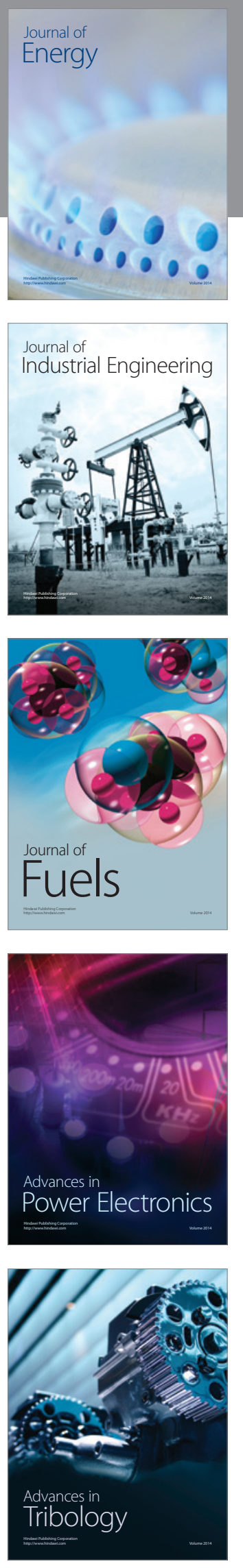
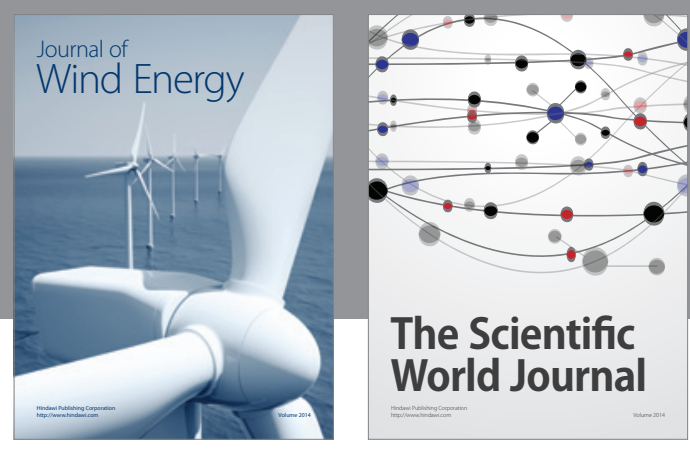

The Scientific World Journal

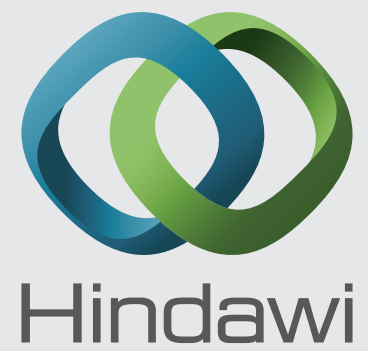

Submit your manuscripts at http://www.hindawi.com
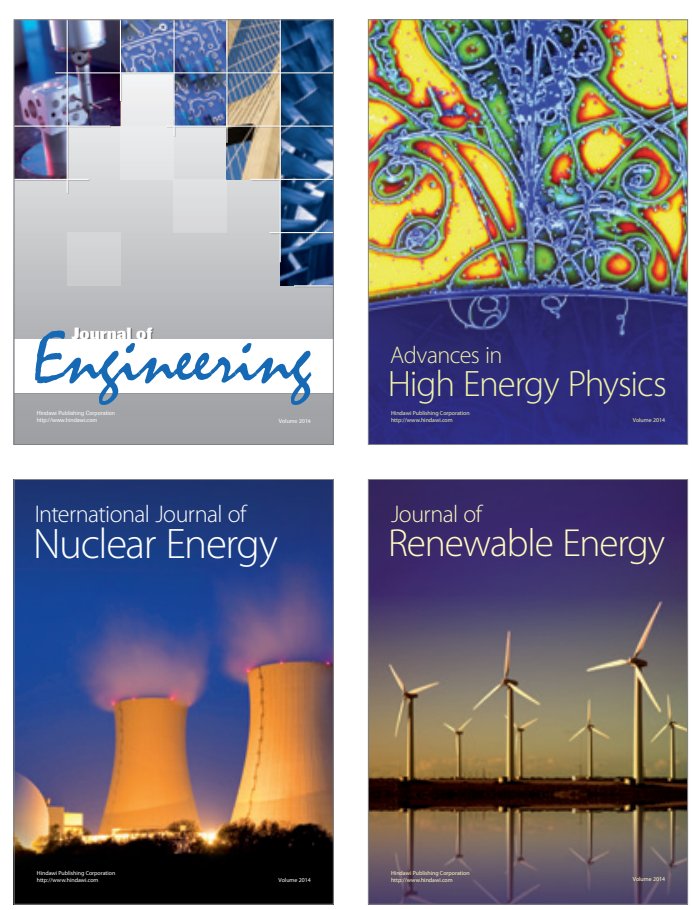

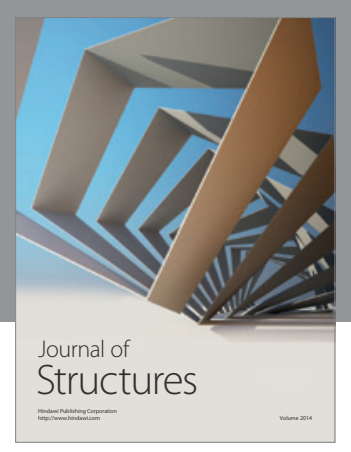

Rotating
Mechinery
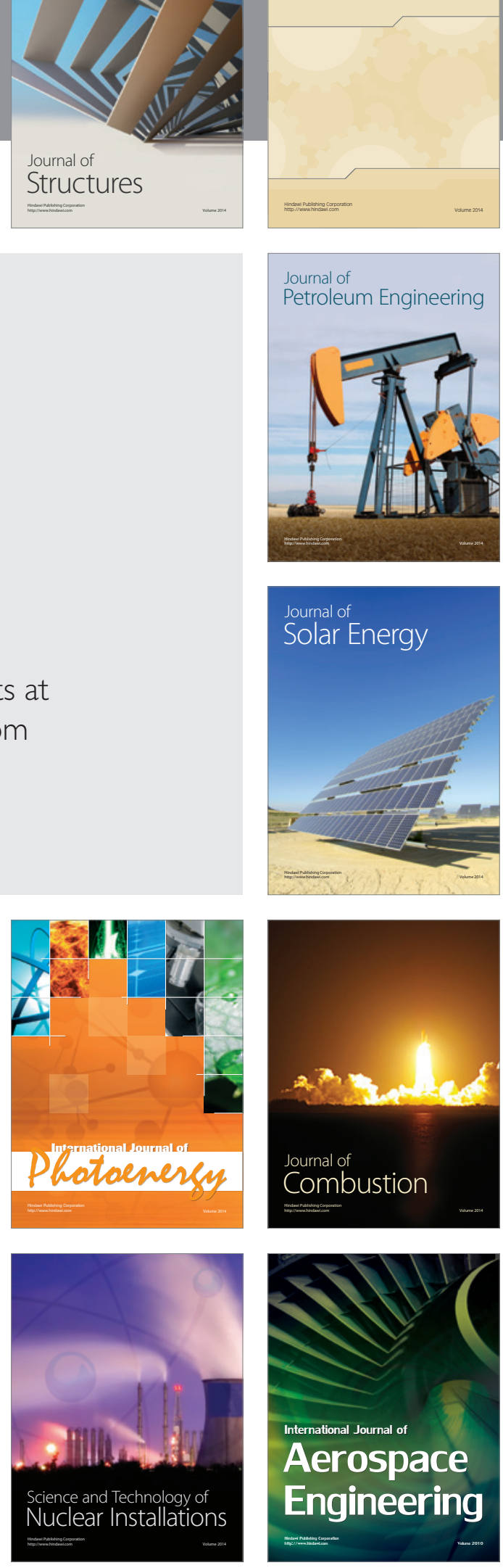